\title{
Experimental and theoretical evaluation of new 3,3'-methylenedianiline Schiff bases as corrosion inhibitors for carbon steel in sulfuric acid
}

\section{E.A. Flores-Frias, ${ }^{1}$ A. Gonzalez-Hernandez, ${ }^{2}$ V. Barba, ${ }^{2}$ R. Lopez-Sesenes, ${ }^{3}$ L.L. Landeros-Martinez, ${ }^{4}$ (i) J.P. Flores-De los Rios $^{5}$ (i) and J.G. Gonzalez-Rodriguez ${ }^{1}$ (D)}

${ }^{1}$ Universidad Autonoma del Estado de Morelos, CIICAp, Av. Universidad 1001-62209Cuernavaca, Morelos, Mexico

${ }^{2}$ Universidad Autonoma del Estado de Morelos, CIQ, Av. Universidad 1001-62209Cuernavaca, Morelos, Mexico

${ }^{3}$ Universidad Autonoma del Estado de Morelos, FCQI, Av. Universidad 1001-62209Cuernavaca, Morelos, Mexico

${ }^{4}$ Universidad Autonoma de Chihuahua, Facultad de Ciencias Quimicas, Circuito No.1, Campus Universitario 2, C.P. 31125, Chihuahua, Chihuahua, Mexico

${ }^{5}$ Tecnologico Nacional de Mexico, Instituto Tecnologico de Chihuahua, Av. Tecnologico \#2909, C.P. 31310, Chihuahua, Chihuahua, Mexico

*E-mail: ggonzalez@uaem.mx

\begin{abstract}
Three Schiff bases were synthesized from 3,3'-methylenedianiline and used as corrosion inhibitors for 1018 carbon steel in $0.5 \mathrm{M}$ sulfuric acid. New compounds include 3-bromosalicylaldehyde (BSD), 5-nitro-salicylaldehyde (NSD) and 2-hydroxy-naphtaldehyde (HND). They were evaluated by means of gravimetric tests as well as potentiodynamic polarization curves and electrochemical impedance spectroscopy measurements. Tests were complemented by theoretical calculations using the density functional theory (DFT). The results have shown that the evaluated Schiff bases act as good mixed-type corrosion inhibitors with an inhibitor efficiency that increased with an increase in their concentration and decreased in the series NSD $>$ HND > BSD. They are adsorbed on to the steel surface by a combination of physisorption and chemisorption, dominated by a weak, physical type of adsorption following a Temkin adsorption isotherm. The corrosion process was controlled by the adsorption/desorption of some intermediate species for inhibitor concentrations lower than $100 \mathrm{ppm}$, whereas for higher inhibitor concentrations, the process was under charge transfer control. The theoretical results obtained from the quantum chemical studies showed that parameters such as HOMO, LUMO, dipolar moment, hardness, electronegativity, electron affinity, ionization potential and electrophilicity made NSD the compound which had the best inhibitory properties, in good agreement with the experimental findings. Analysis of Fukui indices for the three molecules revealed nucleophilic and electrophilic sites responsible for electron donation and acceptance.
\end{abstract}


Keywords: Schiff bases, acid corrosion, quantum chemistry.

\section{Introduction}

Corrosion is the destructive attack of metals by its environment that causes huge economic losses due to metal destruction. The spontaneous destruction of metal due to heterogeneous chemical reaction is the chemical corrosion. One of the most effective ways to mitigate corrosion is the use of corrosion inhibitors. The corrosion inhibition involves the adsorption either in a physical, chemical or a combination of both of them of the organic compounds on the metal surface to form protective films [1]. Many organic compounds containing Oxygen, Nitrogen and Sulphur have been studied as corrosion inhibitors for metals. Corrosion inhibitors are of great practical importance, being extensively employed in minimizing metallic waste in engineering material [2-7].

Schiff bases, which are potential chelating ligands in coordination chemistry [8], show promising applications in medicine as anti-oxidant, antimicrobial and anti-inflammatory agents $[8,9]$. On industrial scale, they have a wide range of applications such as dye and pigment precursors as well as corrosion inhibitors $[9,11]$.

Compounds with $\pi$-bonds also generally exhibit good inhibitive properties due to the interaction of a $\pi$-orbital with the metal surface $[12,13]$. Schiff bases have both above features combined with their structure which make them effective potential corrosion inhibitors for steel, cooper and aluminum [14-26]. Several Schiff base metal complexes have been investigated as corrosion inhibitors. It has been demonstrated that the presence of aromatic rings parallel to the surface enhances the adsorption of an organic compounds in addition to the molecule's electronic structure, thus affecting their inhibition efficiency. Thus, in this research work, the inhibition efficiency of three Schiff base inhibitors synthetized by the reaction of 3,3'-methylenedianiline and aldehydes for carbon steel in sulfuric acid is reported [27]. This material was chosen because it is widely used in acid pickling, industrial cleaning, acid decaling, oil well acid treatment in oil recovery, and petrochemical processes where acids are used. This makes important the study of steel corrosion phenomena for industrial and has become an academic topic in recent years $[28,29]$. The main acids abundantly used in these industries are hydrochloric acid, $\mathrm{HCl}$, and sulfuric acid, $\mathrm{H}_{2} \mathrm{SO}_{4}$. Sulfuric acid was used in this study.

\section{Experimental procedure}

\subsection{Synthesis of Schiff base inhibitors}

Details of the synthesis of the Schiff bases are described elsewhere [27] and a brief description is given here. The compounds synthesized included 3-bromo-salicylaldehyde (BSD), 5-nitro-salicylaldehyde (NSD) and 2-hydroxy-naphtaldehyde (HND). For the formation of the Schiff bases, 3,3'-methylenedianiline was used as the main reagent. For the

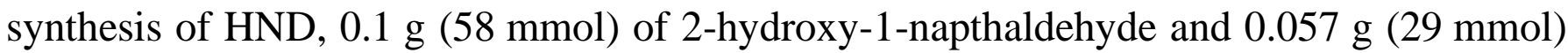
of $3,3^{\prime}$-methylenedianiline were used to give a yellow solid in $93 \%$ yield. For the synthesis 
of NSD $0.1 \mathrm{~g}$ (59 mmol) of nitro-salicylaldehyde and $0.059 \mathrm{~g}$ (29 mmol) of 3,3'methylenedianiline were used, also to give a yellow solid in $93 \%$ yield. Finally, for the synthesis of BSD, $0.1 \mathrm{~g}$ (49 mmol) of 5-bromosalicylaldehyde and $0.0499 \mathrm{~g}(24 \mathrm{mmol})$ of $3,3^{\prime}$-methylenedianiline were used to give an orange solid in $91 \%$ yield. The compounds were characterized by Infrared spectroscopy in a Nicolet 6700 Thermo Scientific FT-IR Spectrophotometer. Molecular characterization was performed by $1 \mathrm{H}$ and $13 \mathrm{C}$ NMR in a Varian Unit 400 spectrophotometer.

\subsection{Weight loss tests}

The material used in this research work was 1018 carbon steel with a chemical composition given in Table 1. Weight loss experiments were performed by exposing carbon steel rods to a solution of sulfuric acid containing different concentrations of inhibitors for $72 \mathrm{~h}$ at room temperature. All the tests were performed in triplicate. After exposure, specimens were taken out, washed with distilled water, degreased with acetone, dried and weighed accurately according to ASTM G1 standard. The corrosion rate, $\Delta W$, in $\mathrm{mg} / \mathrm{cm}^{2} \mathrm{~h}^{-1}$ was calculated by subtracting the final weight to the initial weight and dividing it by the initial specimen area and the total exposure time. The inhibitor efficiency, I.E., was calculated by the following equation:

$$
\text { I.E. }(\%)=\frac{\Delta W_{1}-\Delta W_{2}}{\Delta W_{1}} \cdot 100
$$

were $\Delta W_{1}$ is the corrosion rate without an inhibitor and $\Delta W_{2}$ is the corrosion rate with an inhibitor. The metal surface area covered by the inhibitor, $\theta$, was calculated by the following equation:

$$
\theta=\frac{I . E}{100}
$$

which is valid for inhibitors with a blocking mechanism of action.

Table 1. Composition of 1018 carbon steel.

\begin{tabular}{cc}
\hline Element & Content (wt. \%) \\
\hline Fe & Balance \\
$\mathrm{C}$ & 0.14 \\
$\mathrm{Mn}$ & 0.60 \\
$\mathrm{~S}$ & $<0.05$ \\
$\mathrm{P}$ & $<0.05$ \\
\hline
\end{tabular}




\subsection{Electrochemical techniques}

Electrochemical techniques used in this work include potentiodynamic polarization curves and electrochemical impedance spectroscopy measurements (EIS). For this, a three electrodes cell was used with a saturated calomel electrode and a graphite rod as the reference and counter electrodes, respectively. Before starting the experiments, the specimens were immersed in the solution for 30 minutes until the open circuit potential value was stable. For polarization curves, the specimens were cathodically polarized by applying a potential $700 \mathrm{mV}$ more negative than the free corrosion potential value, $E_{\text {corr, }}$, and then scanning was started in the anodic direction at a scan rate of $1 \mathrm{mV} / \mathrm{s}$ ending at a potential $500 \mathrm{mV}$ more anodic than the $E_{\text {corr }}$ value by using an ACM Instruments potentiostat. The corrosion current density values, $I_{\text {corr }}$, were calculated by Tafel extrapolation. In the EIS tests, an AC signal of $15 \mathrm{mV}$ peak-to-peak at the $E_{\text {corr }}$ value in a frequency range of $0.1-100000 \mathrm{~Hz}$ was applied from a PC4 300 model Gamry potentiostat.

\subsection{Surface characterization}

The surface morphology of the steel samples after immersion for $72 \mathrm{~h}$ in sulfuric acid solutions in the absence and in the presence of $1000 \mathrm{ppm}$ inhibitors were characterized by a high vacuum scanning electron microscope (LEO VP 1450).

\subsection{Quantum-chemical calculations}

As high accuracy is needed for a good description of properties that depend on the electronic structure, a characterization sequence of NSD, HND, and BSD was studied using the Density Functional Theory (DFT) method. This calculation involved approximations for the Becke three-parameter hybrid quantum functional (B3) [30] for the exchange part and the Lee, Yang and Parr (LYP) [31] for the correlation part, in combination with a 6-311G(d,p) polarized basis set. In this case, the used basis set is confirmed by the valence part of a firstrow atom represented by an inner three-Gaussian function and two outer single Gaussians. The inner shell (for nonhydrogen atoms) is represented by a single function with six Gaussian functions. At the next level, polarization functions are added to give additional flexibility to the description of molecular orbitals [32]. These polarization functions are the second-order Gaussians for nonhydrogen atoms and the first-order (p-type) Gaussians for hydrogen. Such functions have been added to the 6-311G split valence basis to give the $6-311 \mathrm{G}(\mathrm{d}, \mathrm{p})$ set (polarization functions on heavy atoms and hydrogen). Geometrical optimizations were performed in both neutral and protonated forms, followed by a frequency calculation to confirm that the structure is at the minimum energy state. Chemical descriptors were calculated first for the gas form, and then for the protonated form to simulate the acid media. In order to have a better correlation with experimental results obtained in aqueous solution and to understand dispersive, repulsive and electrostatic forces between solute and solvent molecules, the IEFPCM solvation method was employed [33, 34]. All computational studies were performed using the Gaussian 09 suite of programs [35]. Density functional 
methodology was used to obtain the frontier molecular orbitals such as the Highest Occupied Molecular Orbital (HOMO) and Lowest Unoccupied Molecular Orbital (LUMO) for each molecule. This methodology provides an excellent framework to define a set of known chemical parameters such as electron affinity $(E A)$ [36], ionization potential (IP) [37], global hardness $(\eta)$ [38], electronegativity $(\chi)$ [39], electrophilicity $(\omega)$ [40], and dipolar moment $(\mu)$ [41]. Another important calculated parameter was the Fukui function. This function is a mathematical expression that defines the sensitivity that a molecular system must have to undergo changes in its electronic density at different sites in its structure. The Fukui function makes it possible to determinate the susceptibility to an electrophilic and nucleophilic attack in the atoms. Equations of the Fukui function are [42]:

$$
\begin{aligned}
f_{\mathrm{k}}^{-} & =\left[q_{\mathrm{k}}(N)-q_{\mathrm{k}}(N-1)\right] \text { for electrophilic attack } \\
f_{\mathrm{k}}^{+} & =\left[q_{\mathrm{k}}(N+1)-q_{\mathrm{k}}(N)\right] \text { for nucleophilic attack }
\end{aligned}
$$

\section{Results and Discussion}

\subsection{Characterization of the inhibitors}

Infrared spectra for the three Schiff bases are given in Figure 1.

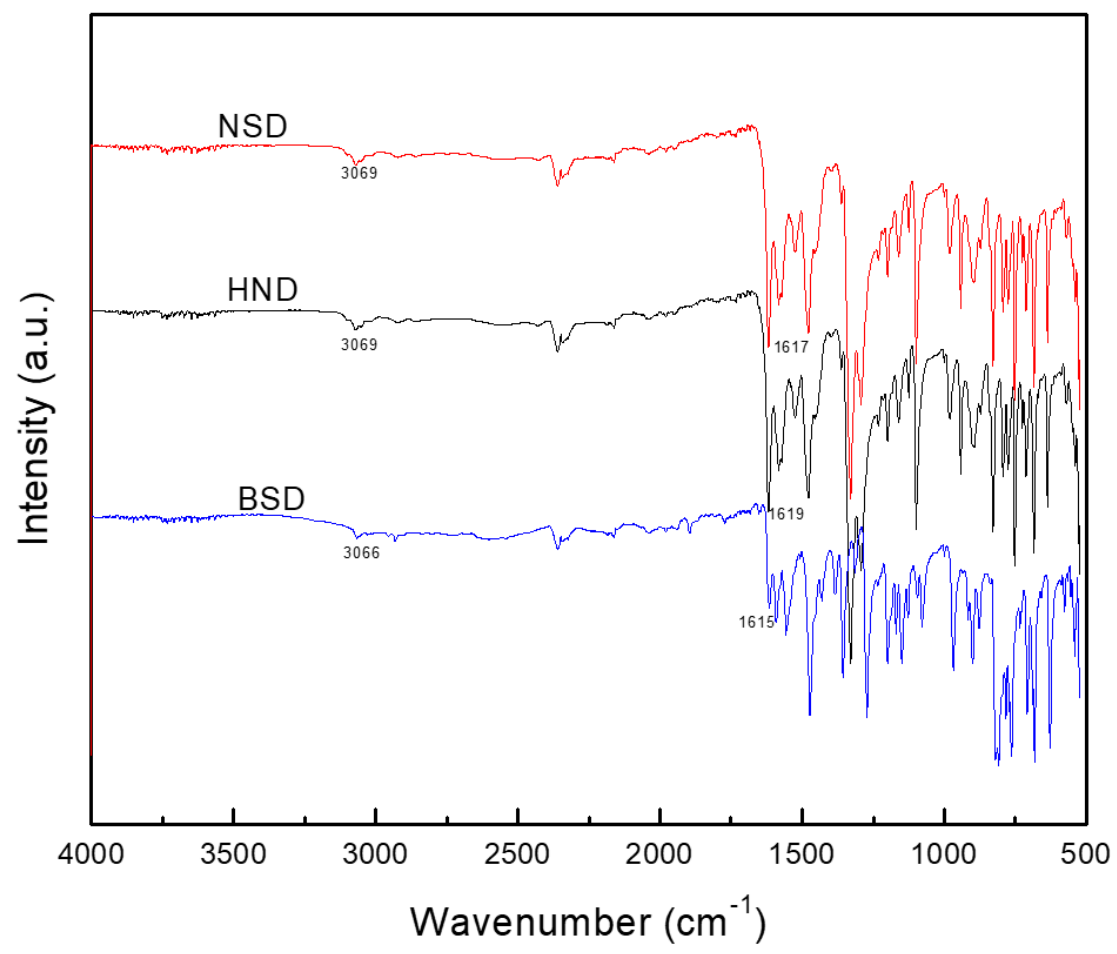

Figure 1. FT-IR spectra of the Schiff bases.

The absorption peaks for the imino group $(C=N)$ are observed at $1615 \mathrm{~cm}^{-1}$ for BSD, $1617 \mathrm{~cm}^{-1}$ for NSD, and at $1619 \mathrm{~cm}^{-1}$ for HND, respectively. On the other hand, the mass 
spectra of the Schiff bases are shown in Figure 2. The most abundant peak for HND observed at an $\mathrm{m} / \mathrm{z}$ value of 506 corresponds to the molecular weight of the Schiff base, giving additional evidence for the formation of this compound. For BSD compound, the most abundant peak observed at an $\mathrm{m} / \mathrm{z}$ value of 564 corresponded to the pattern peak; finally, an abundant peak for NSD observed at $m / z=347$ which does not correspond to the molecular weight, however, the fragmentation corresponds to the molecular structure.
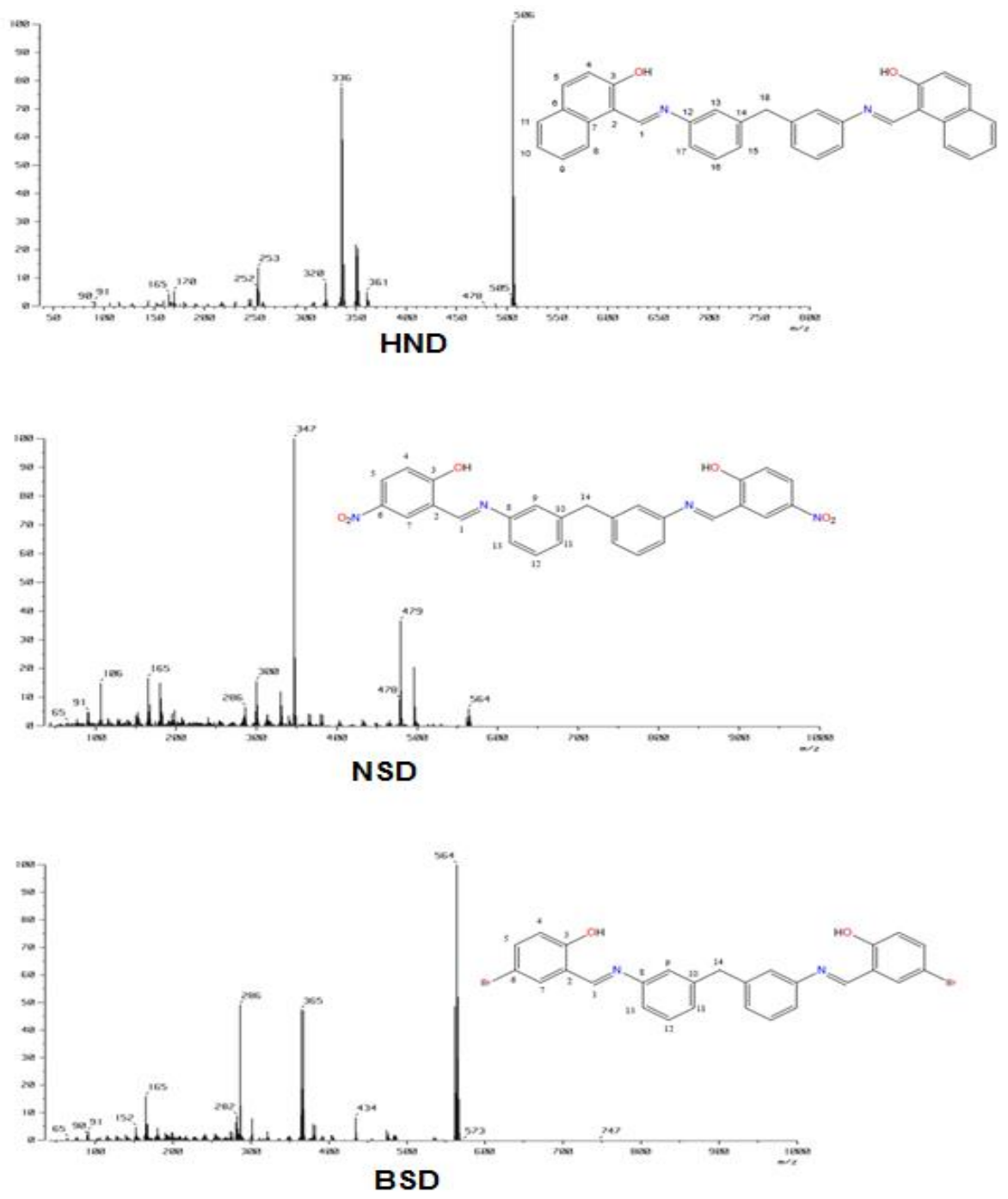

Figure 2. Mass spectra of the Schiff bases.

\subsection{Gravimetric tests}

The effect of the inhibitor concentration on the weight loss, inhibitor efficiency and metal surface area coverage for each of the tested Schiff base compounds is demonstrated in Table 2. It is clear that regardless of the chemical composition, the addition of each of the compounds decreases the corrosion rate of carbon steel, and this decrease increases with the inhibitor concentration. The lowest corrosion rate was obtained with addition of NSD, whereas the highest rate was observed in the presence of BSD. The inhibitor efficiency also 
increases with an increase in the inhibitor concentration to reach the highest value, $96.1 \%$, with addition of NSD, whereas the lowest efficiency, 79.3\%, was reached with addition of BSD. It is also clear that this decrease in the corrosion rate is due to the adsorption of these compounds since the metal surface area covered by the inhibitor, $\theta$, increases with an increase in the inhibitor concentration in the same fashion as the inhibitor efficiency does.

Table 2. Effect of NSD, BSD and HND concentration on the weight loss, inhibitor efficiency and surface area coverage for carbon steel in $0.5 \mathrm{M} \mathrm{H}_{2} \mathrm{SO}_{4}$ solution.

\begin{tabular}{|c|c|c|c|c|}
\hline Compound & $\begin{array}{c}\text { Cinh } \\
(\mathbf{p p m})\end{array}$ & $\begin{array}{l}\text { Weight loss } \\
\left(\mathbf{m g} / \mathbf{c m}^{2} \cdot \mathbf{h}^{-1}\right)\end{array}$ & $\begin{array}{l}\text { I.E. } \\
(\%)\end{array}$ & $\theta$ \\
\hline \multirow{7}{*}{ NSD } & 0 & 1.5 & - & - \\
\hline & 100 & 0.23 & 83.1 & 0.83 \\
\hline & 200 & 0.14 & 89.4 & 0.89 \\
\hline & 400 & 0.13 & 90.7 & 0.90 \\
\hline & 600 & 0.11 & 92.0 & 0.92 \\
\hline & 800 & 0.06 & 95.3 & 0.95 \\
\hline & 1000 & 0.05 & 96.1 & 0.96 \\
\hline \multirow{7}{*}{ BSD } & 0 & 1.5 & - & - \\
\hline & 100 & 0.41 & 66.1 & 0.66 \\
\hline & 200 & 0.37 & 68.5 & 0.68 \\
\hline & 400 & 0.31 & 72.7 & 0.72 \\
\hline & 600 & 0.26 & 78.2 & 0.78 \\
\hline & 800 & 0.25 & 78.2 & 0.78 \\
\hline & 1000 & 0.22 & 79.3 & 0.79 \\
\hline \multirow{7}{*}{ HND } & 0 & 1.5 & - & - \\
\hline & 100 & 0.23 & 73.0 & 0.73 \\
\hline & 200 & 0.17 & 80.2 & 0.80 \\
\hline & 400 & 0.15 & 81.6 & 0.81 \\
\hline & 600 & 0.14 & 81.9 & 0.82 \\
\hline & 800 & 0.12 & 82.5 & 0.82 \\
\hline & 1000 & 0.11 & 84.9 & 0.85 \\
\hline
\end{tabular}

\subsection{Adsorption isotherms}

Since we are assuming that the reduction in the corrosion rate is due to the adsorption of the different organic compounds on to the steel surface, the way that these compounds interact 
with the metal surface can be obtained from the adsorption isotherms. There are different models of such isotherms, but the best fitting was obtained by using the Temkin isotherm such as given in Figure 3. The Temkin isotherm is given by:

$$
\theta=B \ln C_{\text {inh }}+B \ln K_{\text {ads }}
$$

where $B$ is a constant and $K_{\text {ads }}$ the adsorption constant. $K_{\text {ads }}$ is related to the standard free energy of adsorption ( $\Delta G_{\text {ads }}$ ) according to the following equation:

$$
\Delta G_{\text {ads }}=-R T \ln \left(10^{6} K_{\text {ads }}\right)
$$

where $R$ is the universal gas constant and $T$ the absolute temperature. Calculated value for $K_{\text {ads }}$ and $\Delta G_{\text {ads }}$ at room temperature for the three compounds are given in Table 3. It can be seen that the highest $K_{\text {ads }}$ value is for NSD, indicating that this compounds has the strongest adsorption on to the steel surface. Similarly, the lowest $\Delta G_{\text {ads }}$ values is for this compound, $-29 \mathrm{~kJ} / \mathrm{mol}$, whereas that value for HND and BSD were -25.57 and $-22.52 \mathrm{~kJ} / \mathrm{mol}$ respectively, which implies mixture of physisorption and chemisorption, dominated by a weak, physical type of adsorption [40]. The negative value for $\Delta G_{\text {ads }}$ indicates that it is a spontaneous process.

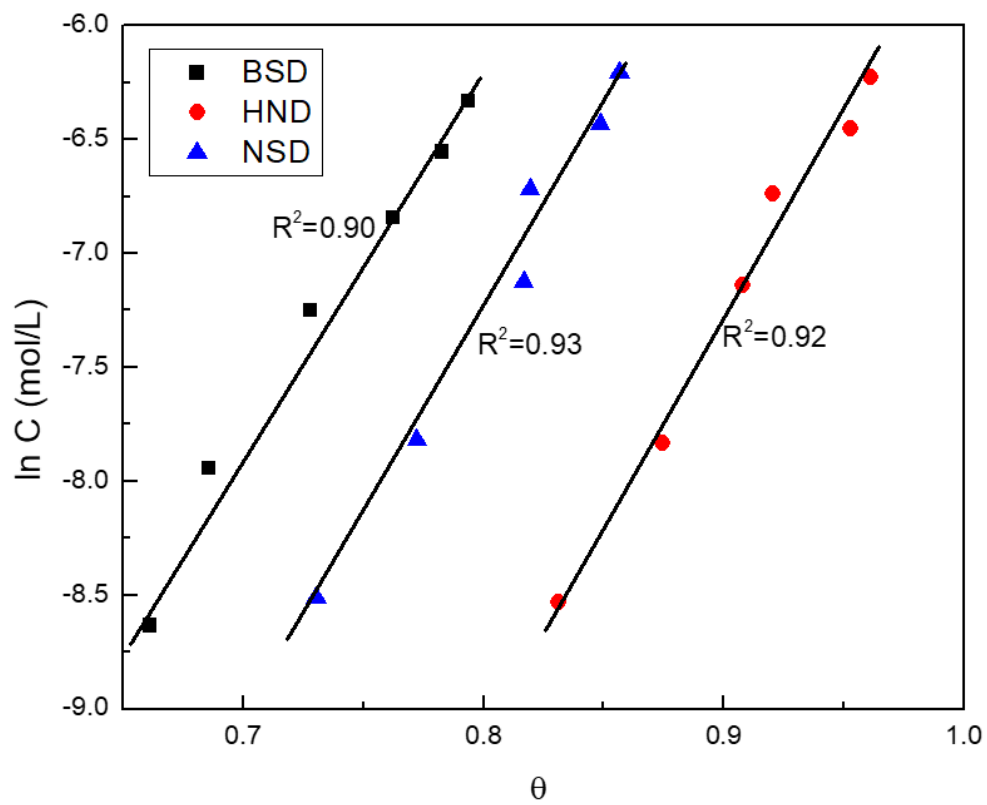

Figure 3. Temkin adsorption isotherm for NSD, HND and BSD.

Table 3. Thermodynamic parameters for NSD, BSD and HND compounds.

\begin{tabular}{ccc}
\hline Compound & $\boldsymbol{K}_{\text {ads }}(\mathbf{L} / \mathbf{m o l})$ & $\Delta \boldsymbol{G}_{\text {ads }}(\mathbf{k J} / \mathbf{m o l})$ \\
\hline NSD & 24245.8 & -29.03 \\
BSD & 8857.3243 & -22.52 \\
HND & 13493.9 & -25.57 \\
\hline
\end{tabular}




\subsection{Potentiodynamic polarization curves}

The polarization curves obtained on carbon steel in $0.5 \mathrm{M} \mathrm{H}_{2} \mathrm{SO}_{4}$ with different concentrations of HND, BSD and NSD are shown in Figure 4, whereas the corresponding electrochemical parameters are given in Table 4. It is clear from the data given in Figure 4 that both cathodic and anodic current density values decrease with addition of these organic compounds, which might be due to their adsorption on the metal surface and to an increase in the metal surface area covered by them as their concentration increases. It is also evident from Table 4 that there is no clear effect of the inhibitors on the $E_{\text {corr }}$ value, i.e., sometimes it shifts towards more active values when the organic compound concentration increases, and in some other cases it shifts towards nobler values, indicating that these compounds behave as mixed-type inhibitors [43-44]. The $I_{\text {corr }}$ values decreased noticeably when these organic compounds were added to the solution. In the case of NSD, this decrease was nearly two orders of magnitude. The corrosion inhibitor efficiency values, I.E., were calculated by the following equation:

$$
I . E .=\frac{I_{\text {corr }}-I_{\text {corr } / \text { inh }}}{I_{\text {corr }}} \cdot 100
$$

where $I_{\text {corr }}$ and $I_{\text {corr/inh }}$ are the corrosion current density values obtained in the absence and in the presence of the inhibitors, respectively.
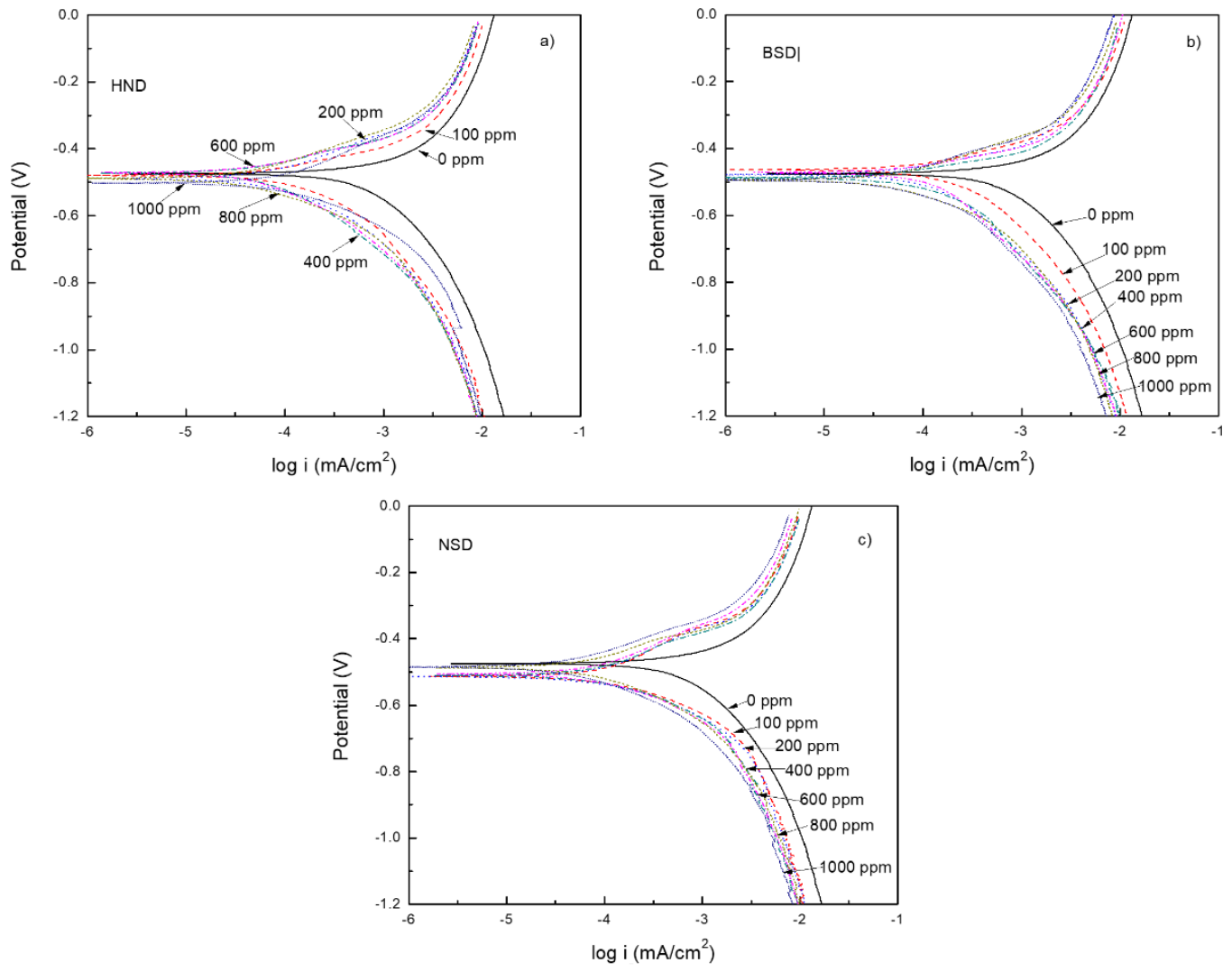

Figure 4. Effect of a)HND, b)BSD and c)NSD concentration on the polarization curves for carbon steel in $0.5 \mathrm{M} \mathrm{H}_{2} \mathrm{SO}_{4}$. 
It can be seen from Table 4 that, regardless of the chemical composition, the inhibitor efficiency value and metal surface coverage, $\theta$, increased with an increase in the inhibitor concentration to reach the highest value when the NSD was used, whereas the lowest inhibitor efficiency was obtained with addition of BSD according to the gravimetric tests. As mentioned above, we can say that these organic compounds behave as mixed-type inhibitors. In this way, it is possible to state that the cathodic reaction is retarded by addition of these organic compounds by blocking of the active sites on the carbon steel surface, whereas the anodic reaction is retarded by the formation of iron complexes due to the presence of a lone electron pair in the structures of the organic compounds [45].

Table 4. Electrochemical parameters obtained from the polarization curves for carbon steel in $0.5 \mathrm{M} \mathrm{H}_{2} \mathrm{SO}_{4}$ solution with different concentrations of NSD, BSD and HND.

\begin{tabular}{cccccc}
\hline Compound & $\begin{array}{c}\boldsymbol{C}_{\text {inh }} \\
(\mathbf{p p m})\end{array}$ & $\begin{array}{c}\boldsymbol{E}_{\text {corr }} \\
(\mathbf{m V})\end{array}$ & $\begin{array}{c}\boldsymbol{I} \text { corr } \\
\left(\mathbf{m A} / \mathbf{c m}^{2}\right)\end{array}$ & $\boldsymbol{I . E .}$ (\%) & $\boldsymbol{\theta}$ \\
\hline \multirow{3}{*}{ NSD } & 0 & -480 & $1 \cdot 10^{-3}$ & - & - \\
& 100 & -475 & $1.25 \cdot 10^{-4}$ & 87 & 0.87 \\
& 200 & -500 & $9.1 \cdot 10^{-5}$ & 90 & 0.90 \\
& 400 & -510 & $7.0 \cdot 10^{-5}$ & 93 & 0.93 \\
& 600 & -510 & $5.0 \cdot 10^{-5}$ & 95 & 0.95 \\
& 800 & -495 & $3.8 \cdot 10^{-5}$ & 96 & 0.96 \\
BSD & 1000 & -490 & $2.5 \cdot 10^{-5}$ & 98 & 0.98 \\
\hline & 100 & -480 & $3.1 \cdot 10^{-4}$ & 70 & 0.70 \\
& 200 & -480 & $1.9 \cdot 10^{-4}$ & 80 & 0.80 \\
& 400 & -490 & $1.2 \cdot 10^{-4}$ & 88 & 0.88 \\
& 600 & -470 & $1.0 \cdot 10^{-4}$ & 90 & 0.90 \\
& 800 & -490 & $8.1 \cdot 10^{-5}$ & 92 & 0.92 \\
HND & 1000 & -500 & $6.5 \cdot 10^{-5}$ & 93 & 0.93 \\
\hline & 100 & -460 & $1.9 \cdot 10^{-4}$ & 80 & 0.80 \\
& 200 & -470 & $1.5 \cdot 10^{-4}$ & 85 & 0.85 \\
& 400 & -480 & $1.3 \cdot 10^{-4}$ & 87 & 0.87 \\
& 600 & -485 & $1.0 \cdot 10^{-4}$ & 90 & 0.90 \\
& 800 & -500 & $8.5 \cdot 10^{-5}$ & 92 & 0.92 \\
& 1000 & -495 & $7.0 \cdot 10^{-5}$ & 93 & 0.93 \\
\hline
\end{tabular}




\subsection{Electrochemical impedance spectroscopy}

The Nyquist plots for 1018 carbon steel in the absence and in the presence of NSD, HND and BSD Schiff bases at different concentrations can be seen in Figure 5. In the absence of these compounds or at doses of $100 \mathrm{ppm}$, the Nyquist plots display a depressed capacitive semicircle at high and intermediate frequencies, whereas at lower frequency values, the presence of an inductive loop is evident, indicating that the corrosion process is controlled by the adsorption/desorption of some intermediate species [46]. Figure 5 clearly shows that, at least at concentrations higher than $100 \mathrm{ppm}$, addition of these compounds changes the corrosion mechanism of carbon steel in sulfuric acid. In fact, at inhibitor concentrations higher than $100 \mathrm{ppm}$, the Nyquist plots display a capacitive semicircle at high and intermediate frequency values followed by some elongations or tails that correspond to a charge transfer controlled corrosion process, which has been attributed to the presence of corrosion products on top of the steel due to the interaction of released iron ions and inhibitor $[47,48]$. It is also clear that the diameter of the capacitive loop increases as the concentrations of the inhibitors increases, which is due to the adsorption of these organic compounds on to the steel surface. The electric circuits used to simulate EIS data are given in Figure 6.
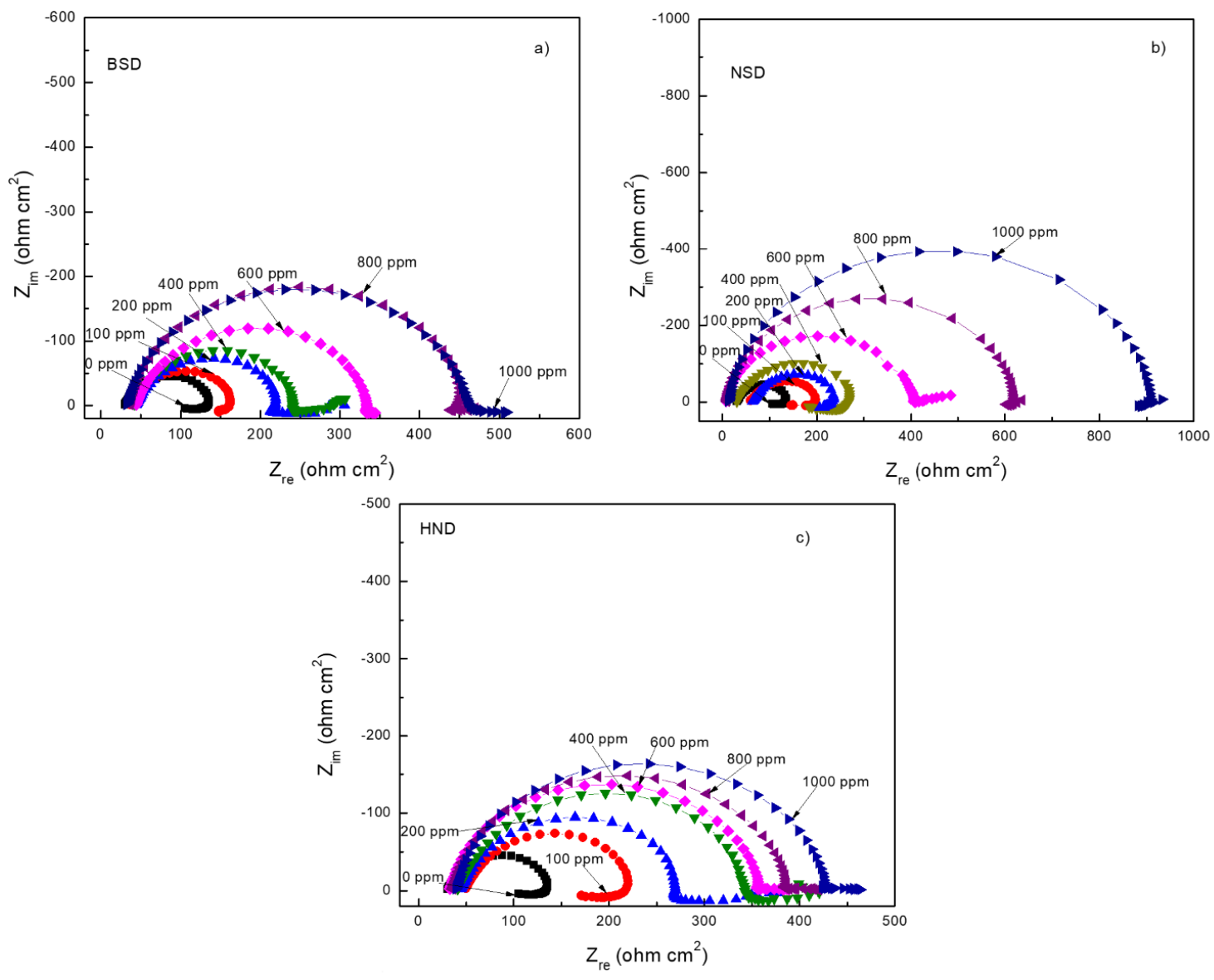

Figure 5. Effect of a) HND, b) BSD and c) NSD concentration on the Nyquist plots for carbon steel in $0.5 \mathrm{M} \mathrm{H}_{2} \mathrm{SO}_{4}$. 

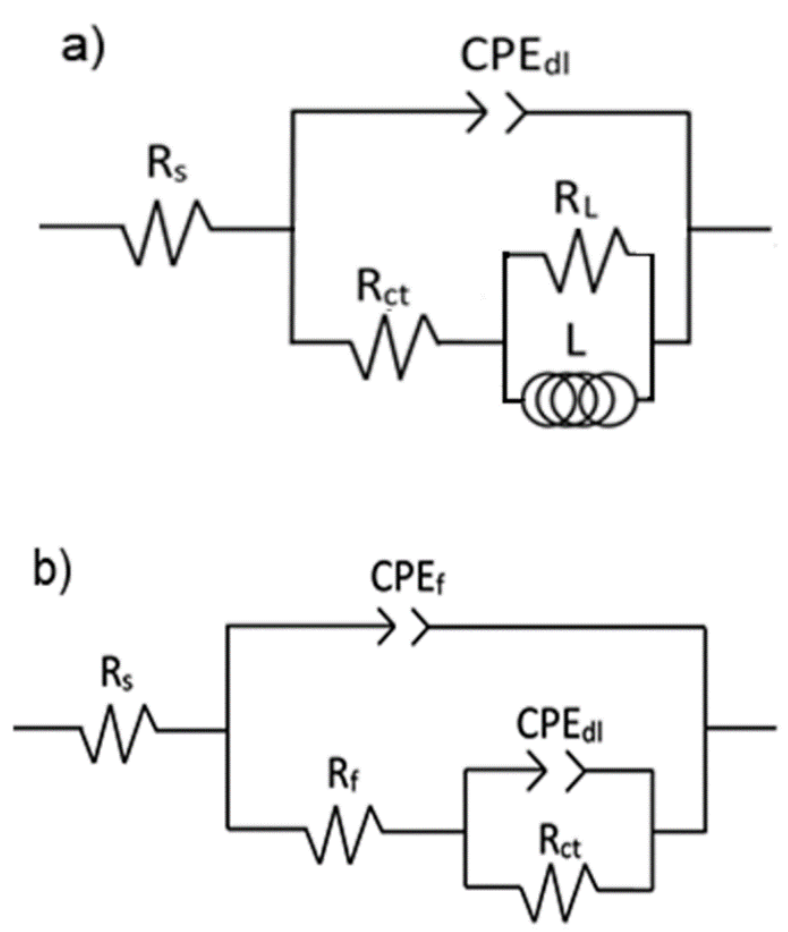

Figure 6. Electric circuits used to simulate EIS data for carbon steel in $0.5 \mathrm{M} \mathrm{H}_{2} \mathrm{SO}_{4}$ a) in the absence and $b$ ) in the presence of HND, BSD and NSD.

In this figure, $R_{\mathrm{s}}$ is the solution resistance, $R_{\mathrm{ct}}$ the charge transfer resistance, $C P E_{\mathrm{dl}}$ is a constant phase element related to the double layer's electrochemical impedance, $R_{\mathrm{f}}$ the resistance of the film formed by the corrosion products and $C P E_{\mathrm{f}}$ is the constant phase element related to its capacitance, $L$ the inductive element and $R_{\mathrm{L}}$ its resistance. $C P E_{\mathrm{dl}}$ and $C P E_{\mathrm{f}}$ are placed instead of an ideal double layer capacitor and film capacitance, $C_{\mathrm{dl}}$ and $C_{\mathrm{f}}$, respectively, to take into account the dispersion effects due to surface roughness and other surface heterogeneities. The impedance of the $C P E, Z_{\mathrm{CPE}}$, is given by [49]:

$$
Z_{\mathrm{CPE}}=\frac{1}{\left[Y_{0}(i \omega)^{n}\right]}
$$

where $Y_{0}$ is the admittance, $i=(-1)^{1 / 2}, \omega$ is the angular frequency and $n$ is a physical parameter which represents the interphase properties of the working electrode such as roughness, inhibitor adsorption, etc. Electrochemical parameters obtained from the fitting of EIS data by using electric circuits shown in Figure 6 are given in Table 5 for both uninhibited and inhibited solutions. From data given in this table, it can be seen that the $R_{\mathrm{ct}}$ values are higher than those for $R_{\mathrm{f}}$, and that they increase with an increase in the inhibitor concentration, which indicates that the decrease in corrosion rate for carbon steel is due to the adsorption of these organic compounds. In addition to this, it is also clear that $C P E_{\mathrm{dl}}$ increases with the inhibitors concentration, which is due to the replacement of the water molecules by the organic molecules of these compounds with the formation of a protective barrier [50, 51]. It is also evident that $R_{\mathrm{ct}}$ and $R_{\mathrm{f}}$ reached their highest values when inhibitor added was NSD, 
followed by HND, and finally, the lowest values were obtained when compound BSD was added. Inhibitor efficiency in this case was obtained by using:

$$
\text { I.E. }=\frac{R_{\mathrm{p} / \text { inh }}-R_{\mathrm{p}}}{R_{\mathrm{p} / \mathrm{inh}}} \cdot 100
$$

where $R_{\mathrm{p}}$ and $R_{\mathrm{p} / \mathrm{inh}}$, the sum of all the resistances across the metal/electrolyte interface, are the polarization resistance values obtained in the absence and in the presence of the inhibitor respectively. It is clear from Table 5 that the inhibitor efficiency decreased in the series NSD > HND > BSD in agreement with the weight loss and polarization curves data.

Table 5. Electrochemical parameters used to simulate EIS data for carbon steel in $0.5 \mathrm{M} \mathrm{H}_{2} \mathrm{SO}_{4}$ solution with different concentrations of NSD, BSD and HND.

\begin{tabular}{|c|c|c|c|c|c|c|c|c|c|c|}
\hline \multicolumn{2}{|c|}{ Compound } & $\begin{array}{c}C P E_{\mathrm{dl}} \\
\left(\mu \mathrm{S} \mathrm{s} \mathbf{S}^{n} / \mathbf{c m}^{2}\right)\end{array}$ & $n$ & $\underset{(\mathbf{O h m}}{\boldsymbol{R}_{\mathrm{ct}}} \cdot$ & 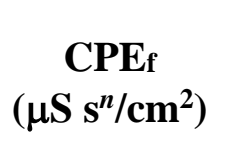 & $n_{\mathrm{f}}$ & $\underset{(\mathbf{O h}}{R_{\mathbf{f}}} \cdot$ & $\underset{\left(\mathbf{O h m}^{R_{\mathbf{L}}}\right.}{\left.\mathbf{c m}^{2}\right)}$ & $\underset{(\mathbf{O h m}}{\boldsymbol{R}_{\mathbf{p}}} \cdot$ & $\begin{array}{l}\text { I.E. } \\
(\%)\end{array}$ \\
\hline \multirow{7}{*}{ HND } & 0 & $9.9 \cdot 10^{-5}$ & 0.8 & 96 & $5.7 \cdot 10^{-4}$ & 0.8 & - & 21 & 117 & - \\
\hline & 100 & $8.9 \cdot 10^{-5}$ & 0.8 & 167 & $2.1 \cdot 10^{-4}$ & 0.8 & - & \multirow[t]{6}{*}{13} & 182 & 35 \\
\hline & 200 & $4.5 \cdot 10^{-5}$ & 0.9 & 209 & $8.7 \cdot 10^{-3}$ & 0.8 & 30 & & 239 & 51 \\
\hline & 400 & $4.4 \cdot 10^{-5}$ & 0.9 & 259 & $1.3 \cdot 10^{-3}$ & 0.9 & 53 & & 309 & 62 \\
\hline & 600 & $4.0 \cdot 10^{-5}$ & 0.9 & 296 & $7.9 \cdot 10^{-4}$ & 0.9 & 74 & & 370 & 73 \\
\hline & 800 & $2.8 \cdot 10^{-5}$ & 0.9 & 348 & $9.1 \cdot 10^{-5}$ & 0.9 & 87 & & 435 & 82 \\
\hline & 1000 & $3.9 \cdot 10^{-5}$ & 0.9 & 379 & $2.1 \cdot 10^{-5}$ & 0.9 & 99 & & 478 & 85 \\
\hline \multirow{6}{*}{ NSD } & 100 & $1.1 \cdot 10^{-5}$ & 0.8 & 116 & $2.1 \cdot 10^{-4}$ & 0.8 & - & \multirow[t]{6}{*}{12} & 128 & 9 \\
\hline & 200 & $8.0 \cdot 10^{-5}$ & 0.8 & 138 & $7.3 \cdot 10^{-4}$ & 0.8 & 9 & & 143 & 18 \\
\hline & 400 & $5.9 \cdot 10^{-5}$ & 0.9 & 264 & $5.2 \cdot 10^{-4}$ & 0.9 & 30 & & 294 & 60 \\
\hline & 600 & $2.5 \cdot 10^{-5}$ & 0.9 & 401 & $5.2 \cdot 10^{-5}$ & 0.9 & 50 & & 452 & 74 \\
\hline & 800 & $2.7 \cdot 10^{-5}$ & 0.9 & 590 & $1.3 \cdot 10^{-5}$ & 0.9 & 60 & & 650 & 83 \\
\hline & 1000 & $1.5 \cdot 10^{-5}$ & 0.9 & 819 & $5.5 \cdot 10^{-6}$ & 0.9 & 70 & & 892 & 89 \\
\hline \multirow{6}{*}{ BSD } & 100 & $8.0 \cdot 10^{-5}$ & 0.8 & 113 & $2.1 \cdot 10^{-4}$ & 0.8 & - & \multirow[t]{6}{*}{12} & 125 & 8 \\
\hline & 200 & $1.3 \cdot 10^{-2}$ & 0.8 & 166 & $5.9 \cdot 10^{-5}$ & 0.8 & 13 & & 181 & 35 \\
\hline & 400 & $2.7 \cdot 10^{-2}$ & 0.9 & 232 & $4.2 \cdot 10^{-5}$ & 0.9 & 36 & & 268 & 56 \\
\hline & 600 & $3.5 \cdot 10^{-5}$ & 0.9 & 301 & $2.5 \cdot 10^{-5}$ & 0.9 & 58 & & 359 & 67 \\
\hline & 800 & $2.9 \cdot 10^{-5}$ & 0.9 & 404 & $7.6 \cdot 10^{-6}$ & 0.9 & 79 & & 483 & 75 \\
\hline & 1000 & $3.0 \cdot 10^{-5}$ & 0.9 & 434 & $3.8 \cdot 10^{-6}$ & 0.9 & 99 & & 533 & 79 \\
\hline
\end{tabular}




\subsection{Micrographs}

SEM micrographs of corroded samples in the absence and in the presence of the HND, NSD and BSD compounds are given in Figure 7. It can be seen from this figure that on the specimen corroded in the uninhibited solution, Figure $7 \mathrm{a}$, the layer of corrosion products formed on the steel surface presents defects such as pores and micro cracks that form paths for the electrolyte to penetrate and corrode the underlying metal. On the other hand, the layers of corrosion products formed in the presence of different organic compounds, Figure $7 \mathrm{~b}, \mathrm{c}$ and $\mathrm{d}$, do not present this type of defects, and, instead, these layers are more compact and hinder the ingress of the electrolyte to corrode the underlying steel surface, with a decrease in the corrosion rate.

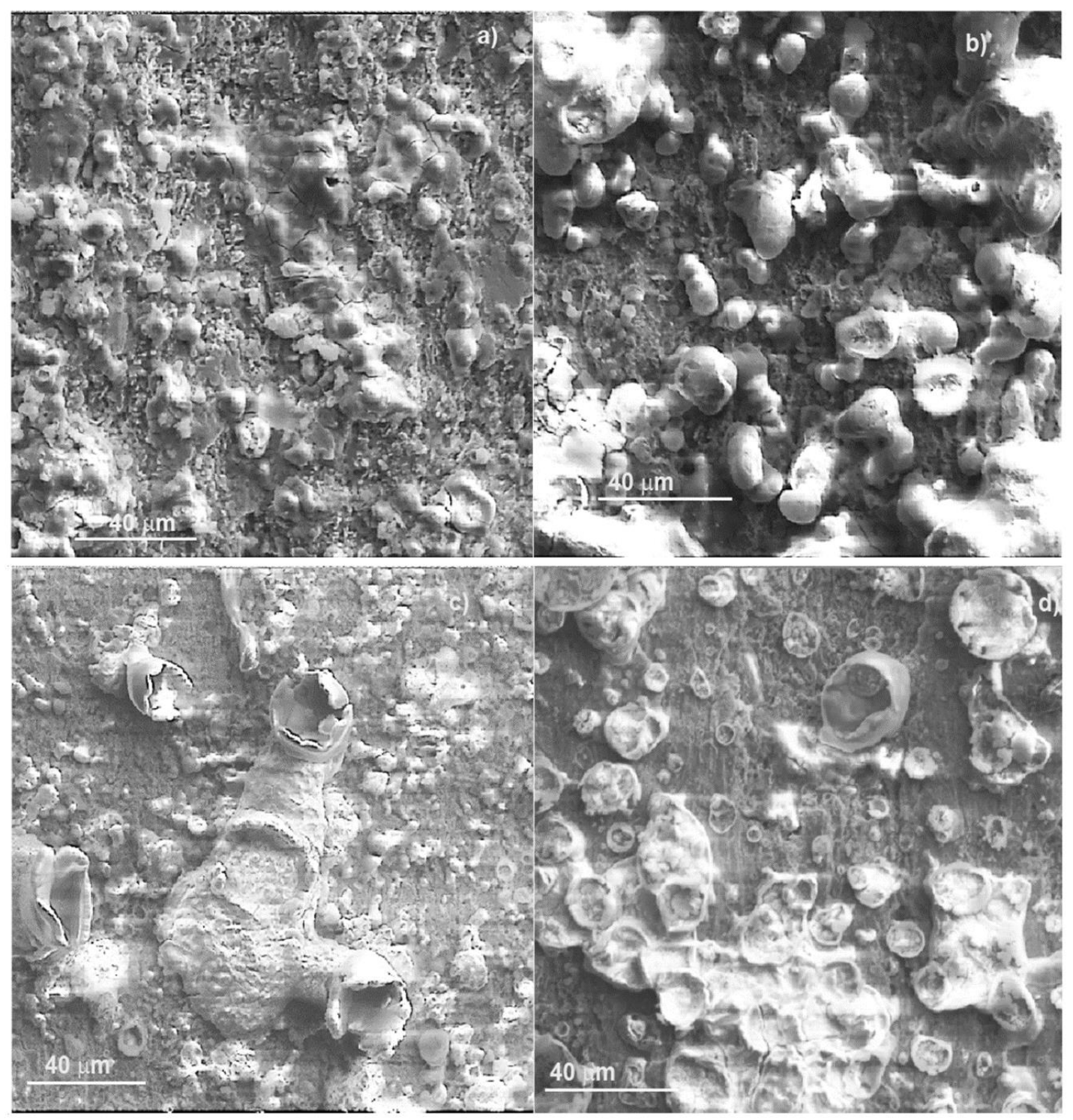

Figure 7. SEM micrographs of 1018 carbon steel corroded in $0.5 \mathrm{M} \mathrm{H}_{2} \mathrm{SO}_{4}$ containing a) 0 , and b) 1000 ppm BSD, c) 1000 ppm HND and d) 1000 ppm NSD. 


\subsection{Quantum chemical calculations}

\section{Neutral molecules}

The optimized structures of neutral molecules are demonstrated in Figure 8, showing the $H O M O$ and $L U M O$ orbitals, whereas the calculated quantum chemical descriptors are given in Table 6. In agreement with the frontier molecular orbital theory, chemical reactivity is a function of interaction between HOMO and $L U M O$ of the reacting species [52]. Higher values of $H O M O$ indicate the ability of a molecule to donate electrons, likewise, lower $L U M O$ values indicates the ability of a molecule to accept electrons [53]. Table 6 indicates more negative values of $H O M O$ for NSD, which indicates a greater efficiency of inhibition of this compound. The hardness is an important property which measures the molecular stability. The resulting values for three molecules are very close, indicating good inhibition properties. Furthermore, the dipole moment is also an important indicator and there is lack of agreement on the correlation between the dipolar moment and inhibitive ability. Some degree of confusion exists when dealing with dipole moment data in the interpretation of inhibition efficiency. A low value will favor the accumulation of an inhibitor on a metal surface, thus increasing the inhibition efficiency [54]. The calculated dipole moment values are 1.45 for BSD, 2.66 for NSD and 4.40 for HND, indicating stronger interaction between the compound and metallic surface [55]. Electrophilicity $(\omega)$, on the other hand, denotes the electron-accepting capability of the molecule, decreased in the order NSD $>$ HND $>$ BSD, confirming that NSD has the highest ability to accept electrons among the three molecules studied. The same behavior is presented by calculations of $I P, E A, \chi$ and $\eta[56,57]$. 
a)

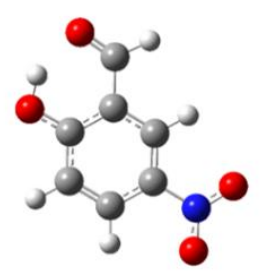

b)

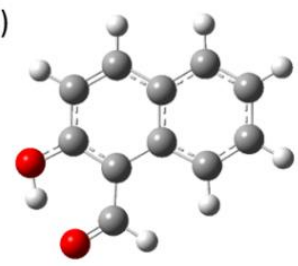

c)

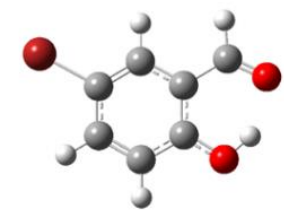

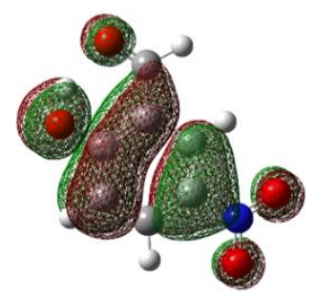
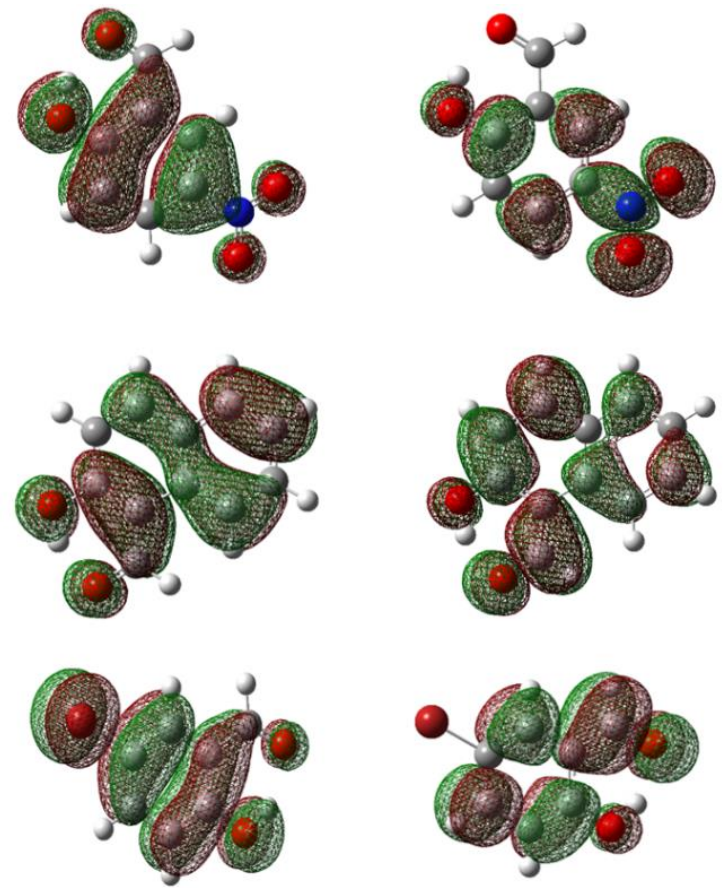

Figure 8. Optimized molecular structures of molecules showing the HOMO and LUMO orbitals for a) NSD, b) HND, c) BSD Schiff bases. The atomic colors are gray (C), white (H), red $(\mathrm{O})$, blue $(\mathrm{N})$ and brown $(\mathrm{Br})$.

Further analysis of Fukui functions is shown in Figure 9. In the NSD molecule there is a nucleophilic attack in the atom $\mathrm{C} 2$, the electrophilic attack occurs in the atom O11. For $\mathrm{HND}$, the nucleophilic attack is in the atom $\mathrm{C} 4$, and the electrophilic attack is in atom C7. In the BSN molecule, the nucleophilic attack and electrophilic attack are presented in the Br13 and $\mathrm{C} 4$ atoms, respectively. It has been found that the sites with electrophilic attack are favored by $H O M O$ energies, respectively, LUMO sites are most susceptible to nucleophilic attack [58].

Table 6. The calculated quantum chemical descriptors for NSD, HND and BSD molecules obtained using DFT at the B3LYP/6-311G(d,p) basis set in aqueous phase.

\begin{tabular}{cccccccccc}
\hline $\begin{array}{c}\text { Neutral } \\
\text { molecules }\end{array}$ & $\begin{array}{c}\text { HOMO } \\
(\mathbf{e V})\end{array}$ & $\begin{array}{c}\boldsymbol{L U M O} \\
(\mathbf{e V})\end{array}$ & $\begin{array}{c}\Delta \boldsymbol{E} \\
(\mathbf{e V})\end{array}$ & $\begin{array}{c}\boldsymbol{\mu} \\
(\mathbf{D e b y e})\end{array}$ & $\begin{array}{c}\boldsymbol{I P} \\
(\mathbf{e V})\end{array}$ & $\begin{array}{c}\boldsymbol{E A} \\
(\mathbf{e V})\end{array}$ & $\begin{array}{c}\boldsymbol{\chi} \\
(\mathbf{e V})\end{array}$ & $\begin{array}{c}\boldsymbol{\eta} \\
(\mathbf{e V})\end{array}$ & $\begin{array}{c}\boldsymbol{\omega} \\
(\mathbf{e V})\end{array}$ \\
\hline NSD & -7.22 & -2.76 & 4.46 & 2.66 & 7.19 & 2.74 & 4.97 & 2.23 & 5.53 \\
HND & -6.32 & -2.32 & 4.00 & 4.40 & 6.24 & 2.42 & 4.33 & 1.91 & 4.90 \\
BSD & -6.59 & -2.33 & 4.25 & 1.45 & 6.55 & 2.40 & 4.48 & 2.07 & 4.83 \\
\hline
\end{tabular}




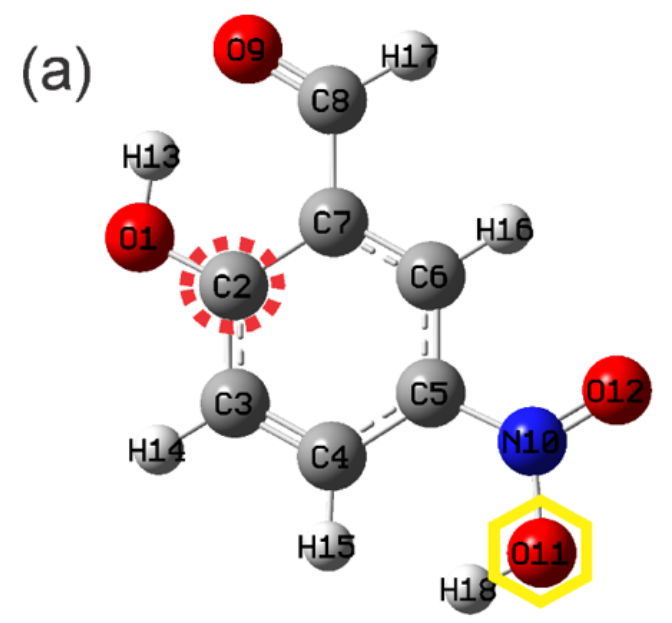

( c)

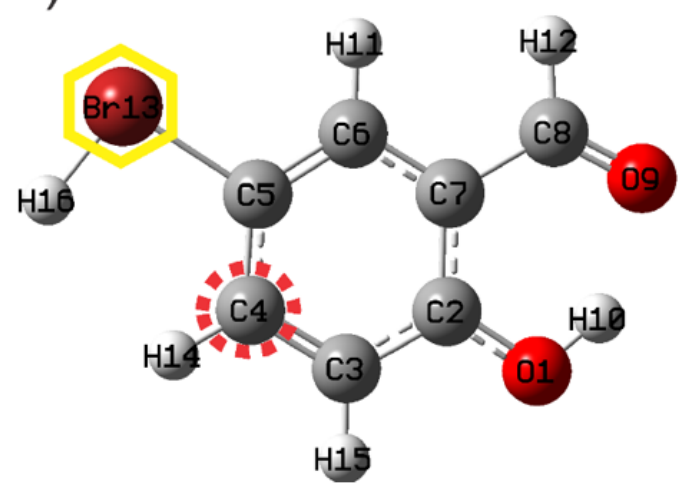

(b)
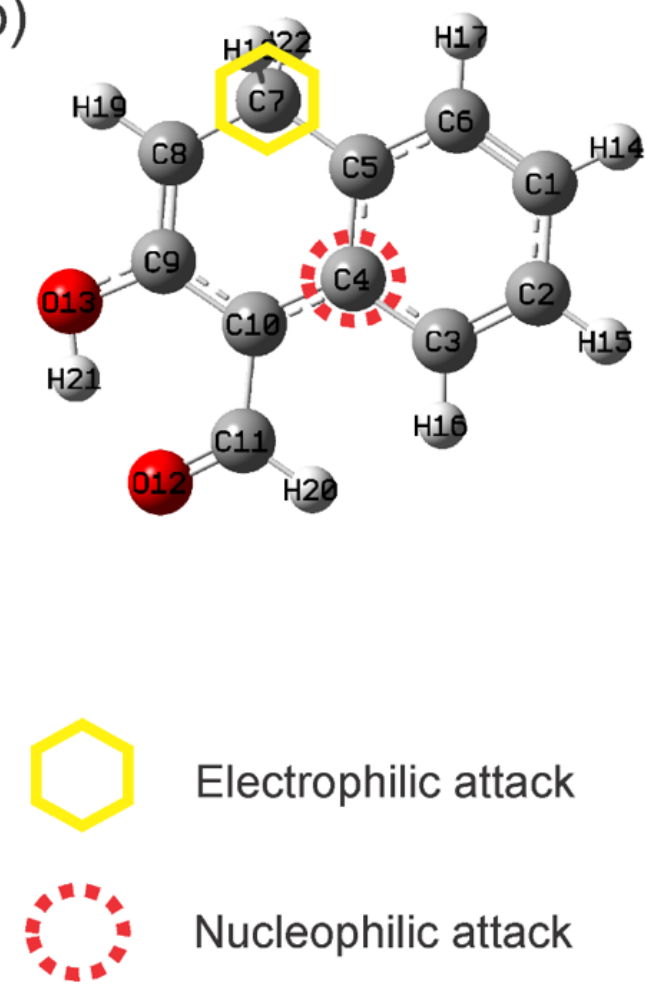

Electrophilic attack

Nucleophilic attack

Figure 9. Fukui function distribution for electrophilic attack and nucleophilic attack for the a) NSD, b) HND and c) BSD molecules.

\section{Protonated molecules}

Optimized structures of the NSD, HND, and BSD Schiff bases molecules in their neutral states contain more than one active center for protonation according to the electronic density observed in HOMO that corresponds to the electrophilic attack, Figure 9. Thus, the protonation site of the molecule was determined through the Fukui functions. According to Fukui function, the most susceptible sites for an electrophilic attack in NSD, HND, BSD are located on the O11, C7 and B13 atoms, respectively. The electronic parameters of the protonated inhibitor molecules such as HOMO, LUMO, $\triangle E$, dipole moment and reactivity parameters are shown in Table 7. The optimized structures as well as HOMO and LUMO are shown in Figure 10 also. In $H O M O$, values vary in the order NSD > BSD > HND, with values of $-8.20,-7.54$ and -7.53 , respectively, which indicates a greater efficiency of inhibition of the NSD molecule. The dipole moment $(\mu)$ in the protonated inhibitor follows the trend NSD $<$ HND $<$ BSD, where the low values indicates a great adsorption of the molecule on the metal surface, thus improving the corrosion inhibition. The electronegativity $(\chi)$ measures the capacity of an atom to attract electrons [59] which are commonly considered 
in corrosions studies. Therefore, high values of $\chi$ indicate better attraction properties, thus increasing the inhibitory effect. In the result obtained for the neutral and protonated molecules, NSD presents the best characteristics of electronegativity; according to [59], the electronegativity is one of the parameters that provides important clues about the corrosion inhibition efficiency of any chemical species. On the other hand, Figure 11 shows the molecular electrostatic potential $(M E P)$ of protonated molecules. All the molecules have a blue region, i.e., these protonated molecules have the most positive electrostatic potential.

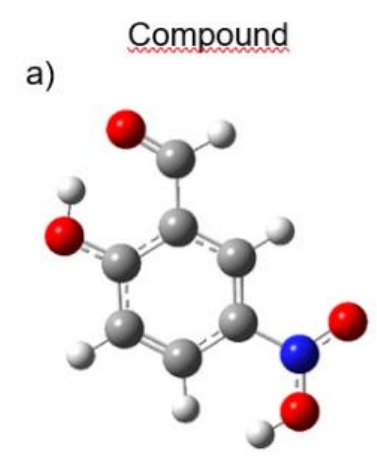

b)

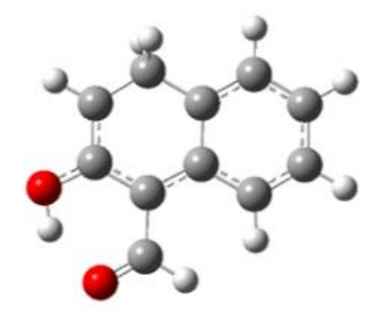

c)

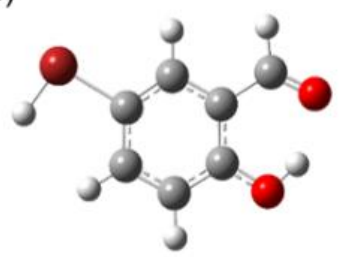

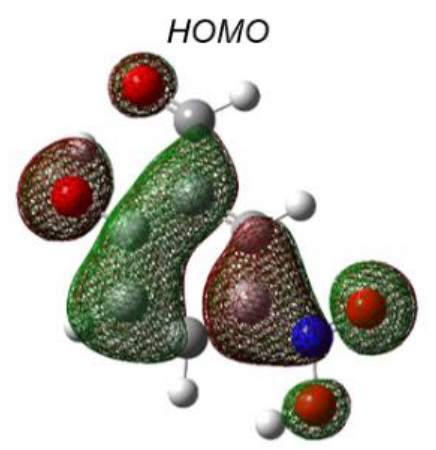
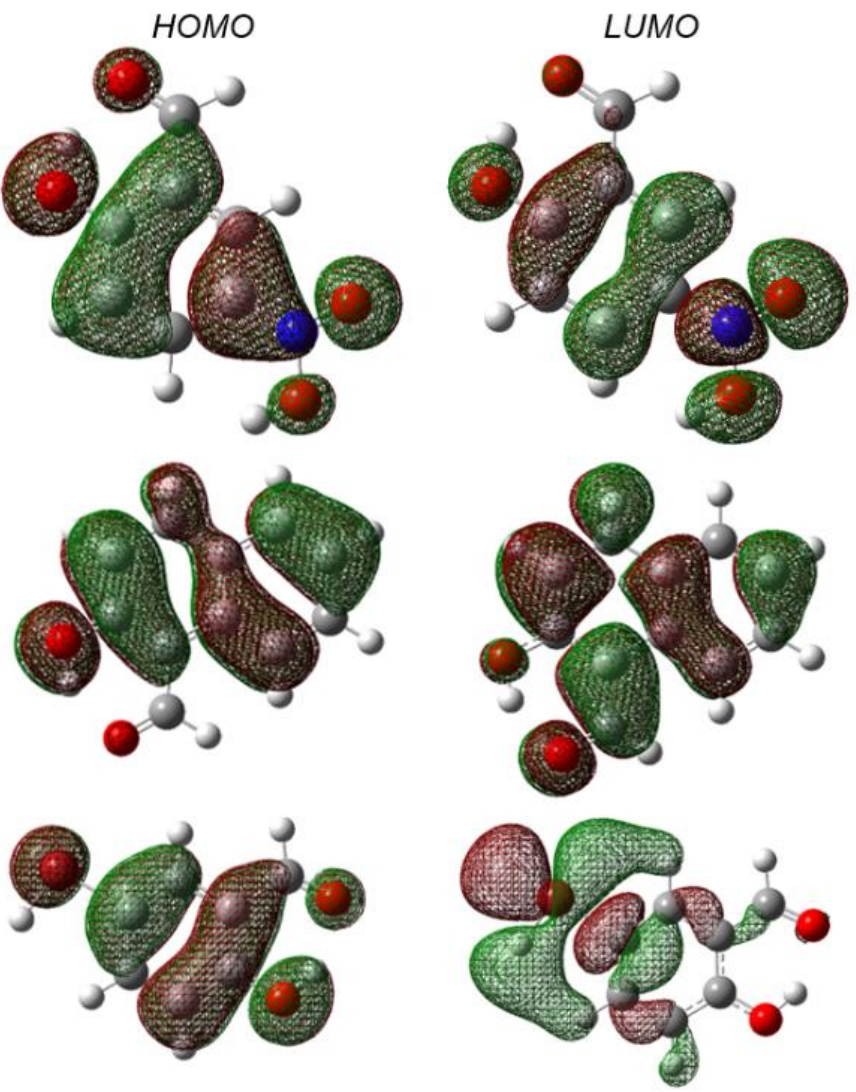

Figure 10. Optimized molecular structures of molecules protonated, $H O M O$ and $L U M O$ orbitals for a) NSD, b) HND and c) BSD. Atomic colors are gray $(\mathrm{C})$, white $(\mathrm{H})$, red $(\mathrm{O})$, blue $(\mathrm{N})$ and brown $(\mathrm{Br})$.

Table 7. The calculated quantum chemical descriptors for protonated NSD, HND and BSD molecules set in aqueous phase.

\begin{tabular}{cccccccccc}
\hline $\begin{array}{c}\text { Protonated } \\
\text { molecules }\end{array}$ & $\begin{array}{c}\text { HOMO } \\
(\mathbf{e V})\end{array}$ & $\begin{array}{c}\text { LUMO } \\
(\mathbf{e V})\end{array}$ & $\begin{array}{c}\Delta \boldsymbol{E} \\
(\mathbf{e V})\end{array}$ & $\begin{array}{c}\mu \\
(\mathbf{D e b y e})\end{array}$ & $\begin{array}{c}\boldsymbol{I P} \\
(\mathbf{e V})\end{array}$ & $\begin{array}{c}\boldsymbol{E A} \\
(\mathbf{e V})\end{array}$ & $\begin{array}{c}\boldsymbol{\chi} \\
(\mathbf{e V})\end{array}$ & $\begin{array}{c}\boldsymbol{\eta} \\
(\mathbf{e V})\end{array}$ & $\begin{array}{c}\boldsymbol{\omega} \\
(\mathbf{e V})\end{array}$ \\
\hline NSD & -8.20 & -4.74 & 3.46 & 3.45 & 8.16 & 4.78 & 6.47 & 1.69 & 5.53 \\
HND & -7.53 & -5.00 & 2.53 & 5.08 & 7.45 & 5.13 & 6.29 & 1.16 & 17.01 \\
BSD & -7.54 & -2.84 & 4.70 & 11.45 & 7.36 & 2.82 & 5.09 & 2.27 & 5.70 \\
\hline
\end{tabular}


a)

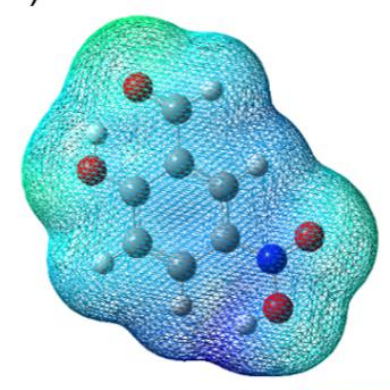

negative b)

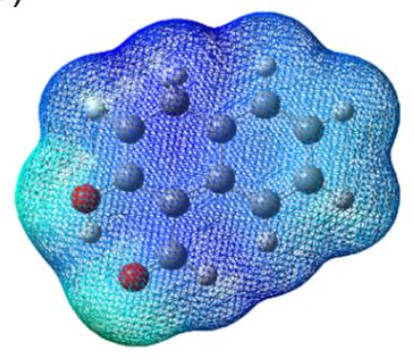

c)

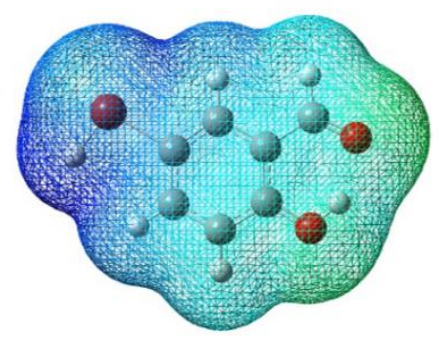

Figure 11. The calculated molecular electrostatic potential $(M E P)$ map the colour range (blue more positive, red more negative) oscillates for a) NSD, $-0.241 \mathrm{e} 0$ from $0.241 \mathrm{e} 0$, b) HND, $-0.171 \mathrm{e} 0$ from $0.171 \mathrm{e} 0$, and c) $\mathrm{BSD},-0.239 \mathrm{e} 0$ from $0.239 \mathrm{e} 0$. Atomic colours are gray $(\mathrm{C})$, white $(\mathrm{H})$, red $(\mathrm{O})$, blue $(\mathrm{N})$ and brown $(\mathrm{Br})$.

\section{Conclusions}

Three Schiff bases, namely 3-bromo-salicylaldehyde (BSD), 5-nitro-salicylaldehyde (NSD) and 2-hydroxy-naphtaldehyde (HND), were synthesized from 3,3'-methylenedianiline and used as corrosion inhibitors for 1018 carbon steel in $0.5 \mathrm{M}$ sulfuric acid. The results obtained indicate that the three compounds behave as efficient corrosion inhibitors, with an efficiency that increases with their concentration but decreased in the following order: NSD > HND > BSD. All the compounds behave as mixed-type inhibitors. They are adsorbed on to the steel surface by concurrent physisorption and chemisorption, dominated by weak physical adsorption following a Temkin adsorption isotherm. The results obtained from the quantum chemical parameters such as HOMO, LUMO, dipolar moment, hardness, electronegativity, electron affinity, ionization potential and electrophilicity showed that the best inhibitory properties should be manifested by NSD Schiff base, in agreement with the experimental findings. We found more relevant results for NSD for conditions neutral and protonated. Fukui indices analysis of the three molecules described the nucleophilic and electrophilic sites responsible for their electron donation and acceptance.

\section{References}

1. H. Wu, F. Kou, F. Jia, B. Liu, J. Yuan and Y. Bai, A V-shaped ligand 1,3-bis(1methylbenzimidazol-2-yl)-2-oxapropane and its $\mathrm{Cu}$ (II) complex: Synthesis, crystal structure, antioxidation and DNA-binding Properties, J. Photochem. Photobiol., B, 2011, 105, no. 3, 190-197. doi: 10.1016/j.jphotobiol.2011.09.001

2. M.A. El-Raouf, E.A. Khamis, M.T.H. Abou Kana and N.A. Negm, Electrochemical and quantum chemical evaluation of new bis (coumarins) derivatives as corrosion inhibitors for carbon steel corrosion in $0.5 \mathrm{M} \mathrm{H}_{2} \mathrm{SO}_{4}$, J. Mol. Liq., 2018, 255, 341-353. doi: $\underline{10.1016 / j . m o l l i q .2018 .01 .148}$ 
3. G. Babaladimath, V. Badalamoole and S.T. Nanibewoor, Electrical conducting Xanthan gum-graft-polyaniline as corrosion inhibitor for aluminum in hydrochloric acid environment, Mater. Chem. Phys., 2018, 205, 171-179. doi: 10.1016/j.matchemphys.2017.11.008

4. S. Bashir, V. Sharma, H. Lgaz, M. Chung, A. Singh and A. Kumar, The inhibition action of analgin on the corrosion of mild steel in acidic medium: A combined theoretical and experimental approach, J. Mol. Liq., 2018, 263 454-462. doi: 10.1016/i.molliq.2018.04.143

5. A. Kahyarian, A. Schumaker, B. Brown and S. Nesic, Acidic corrosion of mild steel in the presence of acetic acid: Mechanism and prediction, Electrochim. Acta, 2017, 258, 639-652. doi: 10.1016/j.electacta.2017.11.109

6. M. Chellouli, D. Chebabe, A. Dermaj, H. Erramli, N. Bettach, N. Hajjaji, M.P. Casaletto, C. Cirrincione, A. Privitera and A. Srhiri, Corrosion inhibition of iron in acidic solution by a green formulation derived from Nigella sativa L, Electrochim. Acta, 2016, 204, 50-59. doi: 10.1016/j.electacta.2016.04.015

7. G. Gece, Drugs: A review of promising novel corrosion inhibitors, Corros. Sci., 2011, 53, 3873-3898. doi: 10.1016/j.corsci.2011.08.006

8. Y. Inada, K. Mochizuki, T. Tsuchiya, H. Tsuji and S. Funahashi, Equilibrium and kinetics of the dinuclear complex formation between $\mathrm{N}, \mathrm{N}^{\prime}$-ethylenebis(salicylideneiminato)copper(II) and metal(II,I) ions in acetonitrile, Inorg. Chim. Acta, 2005, 358, no. 11, 3009-3014. doi: $10.1016 /$ j.ica.2004.12.015

9. M. Arora, J. Saravanan and S. Shivaji Bhattacharjee, Synthesis, characterization and antimicrobial activity of some Schiff bases of 2-amino-n-(p-acetamidophenyl carboxa, Int. J. Pharm. Sci., 2013, 8, no. 21, 1-12.

10. D.S. Zinad, M. Hanoon, R.D. Salim, S.I. Ibrahim, A.A. Al-Amiery, M.S. Takriff and A.A.H. Kadhum, A new synthesized coumarin-derived Schiff base as a corrosion inhibitor of mild steel surface in $\mathrm{HCl}$ medium: gravimetric and DFT studies, Int. J. Corros. Scale Inhib., 2020, 9, no. 1, 228-243, doi: 10.17675/2305-6894-2020-9-1-14

11. A.J.M. Eltmimi, A. Alamiery, A.J. Allami, R.M. Yusop, A.H. Kadhum and T. Allami, Inhibitive effects of a novel efficient Schiff base on mild steel in hydrochloric acid environment, Int. J. Corros. Scale Inhib., 2021, 10, no. 2, 634-648.doi: 10.17675/23056894-2021-10-2-10

12. P. Viswanathamurthi and K. Natarajan, Ruthenium (II) carbonyl complexes containing tetradentate schiff bases and their catalytic activities, Synth. React. Inorg., Met.-Org., Nano-Met. Chem., 2006, 36, no. 5, 415-418. doi: 10.1080/15533170600732619

13. R.N. Patel, Structural, magnetic and spectroscopic characterization of two unusual endon bis(l-acetato/l-nitrato) bridged copper(II) complexes with $\mathrm{N}^{\prime}$-[phenyl(pyridin-2-yl) methylidene]furan-2-carbohydrazide and (2E,4Z)-N,2dimethylhepta-2,4,6-trienamide1-phenyl-1-pyridin-2ylmethanimine (1:1) as capping ligands, Inorg. Chim. Acta, 2010, 363, no. 14, 3838-3846. doi: $10.1016 /$ j.ica.2010.07.026 
14. C. Monticelli, A. Balbo, J. Esvan, C. Chiavaric, C. Martini, F. Zanotto, L. Marvelli and L. Robbiola, Evaluation of 2-(salicylideneimino) thiophenol and other Schiff bases as bronze corrosion inhibitors by electrochemical techniques and surface analysis, Corros. Sci., 2019, 148, 144-158. doi: 10.1016/j.corsci.2018.12.017

15 G. Khan, W.J. Basirun, A. Badarudin, B.M. Badry, S.N. Kazi, P. Ahmed, S.M. Ahmed and G.M. Khan, Corrosion inhibition performance and adsorption mechanism of novel quinazoline schiff base on low alloy steel in $\mathrm{HCl}$ media, Int. J. Electrochem. Sci., 2018, 13, no. 10, 12420-12436.

16. B. Leila, H. Djahida, A. Djamila, M. Saida and C. Salah, Inhibitive properties and quantum chemical calculations of a new synthesized schiff base 1-[(3hydroxyphenylamino) methylene]-naphtalen-2-one for XC48 in Hydrochloric Acid Solution, Int. J. Electrochem. Sci., 2018,13, no. 6, 6734-6755. doi: 10.20964/2018.07.23

17. N. Zakiah, N. Hashim, E.H. Anouar, K. Kassim, H.M. Zaki, A.I. Alharthi and, Z. Embong, XPS and DFT investigations of corrosion inhibition of substituted benzylidene Schiff bases on mild steel in hydrochloric acid, Appl. Surf. Sci., 2019, 476, 861-877. doi: 10.1016/j.apsusc.2019.01.149

18. F. Tezcan, G. Yerlikaya, A. Mahmood and G. Kardaş, Novel thiophene Schiff base as an efficient corrosion inhibitor for mild steel in $1.0 \mathrm{M} \mathrm{HCl}$ : Electrochemical and quantum chemical studies, J. Mol. Liq., 2018, 269, 398-406. doi: 10.1016/j.molliq.2018.08.025

19. S. Vikneshvaran and S. Velmathi, Reinforcement of low-carbon steel against corrosion in acidic condition by some Schiff bases: Experimental and theoretical studies, Mater. Corr., 2018, 69, no. 8, 1084-1094. doi: 10.1002/maco.201709949

20. A. Yurt and O. Aykın, Diphenolic Schiff bases as corrosion inhibitors for aluminum in $0.1 \mathrm{M} \mathrm{HCl}$ : Potentiodynamic polarisation and EQCM investigations, Corros. Sci., 2011, 53, no. 11, 3725-3732. doi: 10.1016/j.corsci.2011.07.018

21. S.R. Gupta, P. Mourya, M.M. Singh and V.P. Singh, Synthesis, structural, electrochemical and corrosion inhibition properties of two new ferrocene Schiff bases derived from hydrazides, J. Organomet. Chem., 2014, 767, 136-143. doi: 10.1016/j.jorganchem.2014.05.038

22. J. Rawat, M. Ajmal and M.A. Quraishi, Dithiobiurets: a novel class of acid corrosion inhibitors for mild steel, J. Appl. Electrochem., 2000, 30, no. 6, 745-751.

23. K.C. Emregul, A.A. Akay and O. Atakol, The corrosion inhibition of steel with Schiff base compounds in $2 \mathrm{M} \mathrm{HCl}$, Mater. Chem. Phys., 2005, 93, no. 2, 325-329. doi: 10.1016/j.matchemphys.2005.03.008

24. K.S. Jacob and G. Parameswaran, Corrosion inhibition of mild Steel in hydrochloric acid solution by Schiff furo in thiosemicarbazone, Corros. Sci., 2010, 52, no. 1, 224-228. doi: $10.1016 /$ j.corsci.2009.09.007

25. S. Issaadi, T. Douadi, A. Zouaoui, S. Chafaa, M.A. Khan and G. Bouet, Novel thiophene symmetrical Schiff base compounds as corrosion inhibitor for mild steel in acidic media, Corros. Sci., 2011, 53, no. 4, 1484-1488. doi: 10.1016/j.corsci.2011.01.022 
26. N.K. Gupta, M.A. Quraishi, C. Verma and A.K. Mukherjee, Green Schiff's bases as corrosion inhibitors for mild steel in $1 \mathrm{M} \mathrm{HCl}$ solution: experimental and theoretical approach, $R S C A d v$., 2016, 104, 102076-102087. doi: 10.1039/C6RA22116E

27. A. Gonzalez-Hernandez, M. Leon-Martínez and V. Barba, Synthesis, characterization and structural analysis of bis-schiff bases using 3,3'-methylenedianiline and salicylaldehyde derivatives, J. Mol. Liq., 2019, 1182, 308-316. doi: 10.1016/j.molstruc.2019.01.061

28. A.H. Ostovari, S.M. Peikari, S.R. Shadizadeh and S.J. Hashemi, Corrosion inhibition of mild steel in $1 \mathrm{M} \mathrm{HCl}$ solution by henna extract: A comparative study of the inhibition by henna and its constituents (Lawsone, Gallic acid, a-D-Glucose and Tannic acid), Corros. Sci., 2009, 51, no. 9, 1935-1943. doi:10.1016/j.corsci.2009.05.024

29. A. Ousslim, A. Aouniti, K. Bekkouch, A. Elidrissi and B. Hammouti, Thermodynamic study of corrosion and inh processes onto C38 steel/piperaines/phosphoric acid systems, Surf. Rev. Lett., 2009, 16, no. 4, 609-615. doi: 10.1142/S0218625X09012949

30. A.D. Becke, Density-functional thermochemistry. III. The role of exact exchange, $J$. Chem. Phys., 1993, 98, no. 2, 5648-5652.

31. C. Lee, W. Yang and R.G. Parr, Development of the Colle-Salvetti conelation energy formula into a functional of the electron density, Phys. Rev B., 1998, 37, no. 6, 785-789. doi: $10.1103 /$ physrevb.37.785

32. P.C. Hariharan and J.A. Pople, The influence of polarization functions on molecular orbital hydrogenation energies, Theor. Chim. Acta., 1973, 28, no. 2, 213-222. doi: $\underline{10.1007 / \mathrm{BF} 00533485}$

33. C. Amovilli, V. Barone, R. Cammi, E. Cancès, M. Cossi and B. Mennucci, Recent Advances in the Description of Solvent Effects with the Polarizable Continuum Model, Adv. Quantum Chem., 1998, 32, 227-261. doi: 10.1016/S0065-3276(08)60416-5

34. B. Mennucci, E. Cancès and J. Tomasi, Evaluation of solvent effects in isotropic and anisotropic dielectrics and in ionic solutions with a unified integral equation method: theoretical bases, computational implementation, and numerical applications, J. Phys. Chem. B, 1997, 101, no. 49, 10506-10517. doi: 10.1021/jp971959k

35. M.J. Frisch, G.W. Trucks, H.B. Schlegel, G.E. Scuseria and M.A. Robb, Gaussian 09, Revision A.02. Gaussian 09, Revision B.01, Gaussian, Inc., Wallingford CT, 2009.

36. J.J.P. Stewart, Optimization of parameters for semiempirical methods V: modification of NDDO approximations and application to 70 elements, J. Mol. Model., 2007, 13, 1173-1213. doi: 10.1007/s00894-007-0233-4

37. E. Lewars, Computational chemistry: introduction to the theory and applications of molecular quantum mechanics, Kluwer, Boston, 2003, 102-109.

38. R.G. Pearson, Absolute electronegativity and hardness correlated with molecular orbital theory, Proc. Natl. Acad. Sci. USA, 1986, 83, 8440-8441. doi: 10.1073/pnas.83.22.8440

39. R.G. Parr, R.A. Donnelly, L. Mel and W.E. Palke, Electronegativity: the density functional viewpoint, J. Chem. Phys., 1978, 68, 3801-3807. doi: $10.1063 / 1.436185$ 
40. P.K. Chattaraj, U. Sarkar and D.R. Roy, Electrophilicity index, Chem. Rev., 2006, 106, 2065-2091.

41. M.V. Putz, N. Russo and E. Sicilia, Atomic radii scale and related size properties from density functional electronegativity formulation, J. Phys. Chem. A, 2003, 107, no. 28, 5461-5465. doi: 10.1021/jp027492h

42. K. Fukui, Theory of Orientation and Stereo selection, Springer-Verlag, New York, 1975, $1-7$.

43. C. Verna, L.O. Olasunkanmi, E.E. Ebenso and M.A. Quraishi, Adsorption characteristics of Green 5-arylaminomethylene pyrimidine-2,4,6-triones on mild Steel Surface in acidic medium: Experimental and computational approach, Results Phys., 2018, 8, 657-670. doi: 10.1016/j.rinp.2018.01.008

44. S.S. Abd El Rehim, M.A.M. Ibrahimm and K.F. Khalid, The inhibition of 4-(20-amino50-methylphenylazo) antipyrine on corrosion of mild steel in $\mathrm{HCl}$ solution, Mater. Chem. Phys., 2001, 70, no. 3, 268-273. doi: 10.1016/S0254-0584(00)00462-4

45. X. Li, S. Deng and H. Fu, Triazolyl blue tetrazolium bromide as a novel corrosion inhibitor for steel in $\mathrm{HCl}$ and $\mathrm{H}_{2} \mathrm{SO}_{4}$ solutions, Corros. Sci., 2011, 53, no. 4, 302-309. doi: $10.1016 /$ j.corsci.2010.09.036

46. H.M. Abd El-Lateef, A.M. Abu-Dief, L.H. Abdel-Rahman, E.C. Sanudo and N. Aliaga-Alcalde, Electrochemical and theoretical quantum approaches on the inhibition of $\mathrm{C} 1018$ carbon steel corrosion in acidic medium containing chloride using some newly synthesized phenolic Schiff bases compounds, J. Electroanal. Chem., 2015, 743, 120-133. doi: 10.1016/j.jelechem.2015.02.023

47. M. Behpour, S.M. Ghoreishi, M. Salavati-Niasari and B. Ebrahimi, Evaluating two new synthesized S-N Schiff bases on the corrosion of copper in 15\% hydrochloric acid, Mater. Chem. Phys., 2008, 107, no. 1, 153-157. doi: 10.1016/j.matchemphys.2007.06.068

48. M. Özcan, I. Dehri and M. Erbil, Organic sulphur-containing compounds as corrosion inhibitors for mild steel in acidic media: correlation between inhibition efficiency and chemical structure, Appl. Surf. Sci., 2004, 236, no. 1-4, 155-164. doi: 10.1016/j.apsusc.2004.04.017

49. R. Solmaz, G. Kardas, M. Culha, B. Yazıcı and M. Erbil, Investigation of adsorption and inhibitive effect of 2-mercaptothiazoline on corrosion of mild steel in hydrochloric acid media, Electrochim. Acta, 2008, 53, no. 20, 5941-5952. doi: 10.1016/j.electacta.2008.03.055

50. I.D. Raistrick, Impedance studies of porous electrodes, Electrochim. Acta, 1990, 25, no. 10, 1579-1586. doi: 10.1016/0013-4686(90)80013-E

51. Q. Li, H.T. Hu and Y.F. Cheng, Corrosion of pipelines in $\mathrm{CO}_{2}$-saturated oil-water emulsion flow studied by electrochemical measurements and computational fluid dynamics modeling, J. Pet. Sci. Eng., 2016, 147, 408-415. doi: $\underline{10.1016 / j . p e t r o l .2016 .09 .011}$ 
52. A.A. Popova, E. Sokolova, S. Raicheva and M. Christov, AC and DC study of the temperature effect on mild steel corrosion in acid media in the presence of benzimidazole derivatives, Corros. Sci., 2003, 50, no. 1, 33-58. doi: 10.1016/S0010-938X(02)00072-0

53. G. Moretti, F. Guidi and G. Grion, Tryptamine as a green iron corrosion inhibitor in $0.5 \mathrm{M}$ deaerated sulphuric acid, Corros. Sci., 2004, 46, no. 2, 387-403. doi: 10.1016/S0010-938X(03)00150-1

54. S. Umoren, I.B. Obot, Z. Gasem and N.A. Odewunmi, Experimental and theoretical studies of red apple fruit extract as green corrosion inhibitor for mild steel in $\mathrm{HCl}$ solution, J. Dispersion Sci. Technol., 2015, 36, no. 6, 789-802. doi: $\underline{10.1080 / 01932691.2014 .922887}$

55. Y. Qiang, S. Zhang, L. Guo, X. Zheng, B. Xiang and S. Chen, Experimental and theoretical studies of four allyl imidazolium-based ionic liquids as green inhibitors for copper corrosion in sulfuric acid, Corros. Sci., 2017, 119, 68-78. doi:10.1016/j.corsci.2017.02.021

56. A. Zarrouk, H. Zarrok, R. Salghi, B. Hammouti, S.S. Al-Deyab, R. Touzani and T.B. Hadda, A theoretical investigation on the corrosion inhibition of copper by quinoxaline derivatives in nitric acid solution, Int. J. Electrochem. Sci., 2012, 7, no. 7, 6353-6364.

57. J. Zhang, G. Qiao, S. Hu, Y. Yan, Z. Ren and L. Yu, Theoretical evaluation of corrosion inhibition performance of imidazoline compounds with different hydrophilic groups, Corros. Sci., 2011, 53, no. 1,147-152. doi:10.1016/j.corsci.2010.09.007

58. M. Finsgar, A. Lesar, A. Kokalj and I. Milosev, A comparative electrochemical and quantum chemical calculation study of BTAH and BTAOH as copper corrosion inhibitors in near neutral chloride solution, Electrochim. Acta, 2008, 53, no. 28, 8287-8297. doi: $10.1016 /$ j.electacta.2008.06.061

59. S. Kaya, B. Tüzün, C. Kaya and I.B. Obot, Determination of corrosion inhibition effects of amino acids: quantum chemical and molecular dynamic simulation study, J. Taiwan Inst. Chem. Eng., 2016, 58, 528-535. doi: 10.1016/j.jtice.2015.06.009 